\title{
7. The classification of the dialects of Dutch
}

1. Introduction

2. Prolegomena to any division of the Dutch dialects into dialect areas

3. Earlier and more recent classifications of the Dutch dialects into dialect areas

4. The classification of Dutch dialects in this book

5. References

\section{Introduction}

This chapter focuses on the present state of the traditional Dutch dialects and the changes that are currently under way. With this goal in mind, we have, largely on synchronic grounds, subdivided the modern dialect landscape of Dutch into a limited number of dialect areas. ("Dutch" here is considered sensu stricto; see ch. 1 [section 3] for the considerations that led us not to include Frisian and its varieties.)

There is a long tradition of attributing Dutch dialects to larger dialect areas. Attempts in this direction were even made long before the scientific study of the Dutch dialects started by the end of the nineteenth century. A striking example of such an approach can be found in the famous dictionary Etymologicum teutonicae linguae siue dictionarium teutonico-latinum (1574) by Cornelius Kiliaen. A few hundred entries are followed by an indication of the region(s) where the lexical variants were used. Kiliaen used abbreviations such as Brab. (= the old Duchy of Brabant?), Fland. (probably the old County of Flanders), Holl. (probably the old County of Holland), Sel. or Zel. (= Zeeland), etc. Later research (cf. mainly Claes 1991) revealed that Kiliaen had excellent intuitions regarding the geographical diversity of the Dutch dialect landscape and that he used his geographical labels fairly adequately.

To a certain extent, the layman of today is also able to situate dialects in bigger areas. $\mathrm{He}$ or she will recognize the Tongeren dialect as a Limburg dialect, the Leuven dialect as a Brabantine dialect, the Ieper dialect as (West) Flemish, etc. This kind of knowledge does not necessarily correspond to the dialectological insights, simply because laymen most often use pre-existing geographical configurations (such as provinces, departments or other official circumscriptions), which do not always appear to be relevant from a linguistic point of view. For example, the Turnhout dialect will be called an 'Antwerp' dialect and the Zwolle dialect an 'Overijssel' dialect, whereas dialectologists would prefer the labels 'Brabantine' and 'Low Saxon', respectively.

From the end of the nineteenth century onwards (Jellinghaus 1892), dialectologists have endeavoured to present well-founded classifications of the Dutch dialects in larger dialect areas. The resulting maps (cf. section 3. for a concise survey) display conspicuous differences in at least four respects: (1) the method that was applied, (2) the territorial demarcation, (3) the global vision on the structure of a dialect landscape and (4) the nomenclature of the distinct areas. This indicates that such a repartition of the spectrum of varieties in dialect areas is far from unproblematic. The main problems that are inherent to such a classification are discussed in the next section. 


\section{Prolegomena to any division of the Dutch dialects into dialect areas}

All present-day dialect researchers agree that the Dutch dialect landscape forms a continuum with few if any abrupt transitions. This is yet another reason why any division of the Dutch dialects into dialect areas is a problematic undertaking. In this section the main problems will be discussed on the basis of a profound analysis of a fair number of existing maps. We will formulate our main observations in four paragraphs; the first two of these concern variation across dialect areas, and the latter two concern variation within dialect areas.

1) The formation of dialect areas (if any) and the degree to which this happens, may differ considerably per linguistic component. We will briefly explain this on the basis of some data for the dialect area which in this book (chs. 12-14) is referred to as 'East Flemish'. This area owes its identity (in the sense of being distinct from adjacent dialect areas) mainly to a number of phonological characteristics, such as the absence of the prelexical correlation between short and long vowels, the postlexical deletion of high continuant consonants in combination with compensatory lengthening of the preceding vowel, and lenition of intervocalic $p, t$ and $k$ (see ch. 12 for details and data). Besides, it occupies an intermediate position between the southwestern and the Brabantine dialect areas, because it shares some phonological phenomena with the southwestern dialects (e.g. the preservation of non-suffixal schwa) and some with the Brabantine dialects (e.g. diphthongization of old $i i$ as in $i j s / \varepsilon^{\mathrm{i}} \mathrm{s} /$ 'ice' and of old $u u$ as in huis $/ \mathrm{h}^{\mathrm{y}} \mathrm{s} /$ 'house'.

In the domain of morphology (inflection) East Flemish dialects also display some unique features (ch. 13), especially with respect to verb inflection (e.g. present tense forms such as $i k$ băka 'I bake', $i k$ ben 'I am' as against West Flemish and Brabantine $i k$ zijn). Apart from this, morphologically, East Flemish also takes up an intermediate position between the West Flemish and South Brabantine dialects, although it shares more features with West Flemish than with southern Brabantine.

Syntactically, East Flemish displays hardly any unique features (cf. ch. 13). In general, it again holds an intermediate position between West Flemish and Brabantine dialects.

With respect to the lexicon (vocabulary), we have not found any map on which the East Flemish area in its entirety differs from the adjacent areas by an exclusive lexeme variant.

Limburg dialects, which are spoken in the southeastern part of the language area, also owe their identity mainly to phonological phenomena such as regressive voice assimilation under certain prosodic conditions (sandhi voicing) and lexical tone, along with a limited number of morphosyntactic peculiarities such as an old gerund, which consists of the verb stem plus suffix -әп' фе:вә (cf. chs. 18 and 19 for related data).

Another nuance relates to the impact of prelexical phonology, which in structural dialectology constituted the most important criterion for the classification in dialect groups. Goossens (1977: 169) argues, correctly, that dialects that have phoneme inventories that are (almost) identical are not necessarily closely related and as such do not necessarily belong to the same dialect group. Historical processes may have generated identical phoneme inventories but all, or at least some of these sounds may have a 
completely different lexical incidence. As an example let us consider short $/ \mathrm{i} /$ in southern Brabantine, East Flemish and southwestern dialects. In the first group /i/ represents Wgm. I (e.g. in vis 'fish', dik 'thick'), in the second group (just like in SD) it represents Wgm. eo (e.g. in vies 'dirty', ziek 'ill', diep 'deep') and in the last group it reflects Wgm. $\hat{\imath}$ (e.g. in wijs 'wise', dijk 'bank', slijm 'slime'). Hence, with respect to phonology, the classification into dialect groups should not only be based on more or less identical phoneme inventories but also on roughly identical lexical incidence of the individual phonemes. Since a phoneme's lexical incidence is largely a result of historical sound changes, the historical dimension cannot be completely neglected in dialect classifications.

In short, it looks as if a geographical classification of the Dutch dialects will be based first and foremost on phonological phenomena. After all, these are most tightly integrated in the linguistic component and our analysis of a large number of dialect maps shows that phonological phenomena usually provide the most clear-cut transitions and the strongest clusters of isoglosses. Nevertheless, wherever available and appropriate, morphosyntactic (e.g. Spruit 2008) characteristics will also be part of our considerations underlying spatial dialect classification.

2) A linear demarcation of dialect areas does not match linguistic reality. Dialect landscapes essentially consist of dialect continua, in which it may be possible to discern 'central areas' (German Kerngebiete, lit. 'core areas') which are structurally coherent and maximally distinct, but in between such areas transition zones often occur, where features of two (or sometimes three) central areas co-occur and constitute mixed areas. Such transition zones are typically characterized by strong clustering of isoglosses such as those used in traditional dialect geography; even these isoglosses are often idealizations of a more complex reality, which normally displays gradual transitions rather than abrupt ones (cf. also Kessler 1995 for a discussion of this matter).

An example of such a transition zone is the area immediately east of that of the Limburg dialects and immediately west of the so-called Ripuarian dialects (the group of dialects of German and Dutch which form the outer northwestern rim of the historical Second or High-German consonant shift, which changed voiceless stops into fricatives or affricates). Dialects in this transition area combine (East-) Limburg features, such as a relatively palatal realisation of the voiced velar fricative, with a subset of the features which are typical for the Ripuarian dialects, such as the variable deletion of final $/ \mathrm{n} / \mathrm{in}$ monosyllabic function words (Hinskens 2009). Moreover, the shift of etymological $/ \mathrm{k} /$ to /ç/ or / $\mathrm{x} /$, demarcated by an isogloss which is known as the Ürdingen-line, has affected a small part of the lexicon, not only of the dialects in the transition area but also in large parts of the east and even central Limburg dialect area.

Despite these considerations, one of our tasks in this chapter is to present a wellmotivated linear demarcation of Dutch dialect areas, for the benefit of the authors of the so-called 'regional chapters' (chs. 9-26) (see section 4 below).

3) A subdivision of dialects in dialect areas should primarily be based on a cluster of exclusive characteristics, but every area will display some degree of internal variation. Certain areas may, at least partly, owe their identity to a particular mixture of features which are also found in adjacent areas. This is schematically shown in Table 7.1: 
Tab. 7.1: Partial overlap between closely related dialects

\begin{tabular}{|c|c|c|c|}
\hline & area $\mathrm{x}$ & area $y$ & area $\mathrm{z}$ \\
\hline ling. variable & a..... & ….a & b \\
\hline ling. variable & $\mathrm{c}$ & d... & $\ldots d$ \\
\hline ling. variable & $\mathrm{e}$ & f... & $\ldots f$ \\
\hline ling. variable & & $\ldots . . \mathrm{g}$ & $\mathrm{h}$ \\
\hline
\end{tabular}

Tab. 7.2: A particular mix in East Flemish

\begin{tabular}{|c|c|c|c|}
\hline & West Flemish & East Flemish & Brabantine \\
\hline $\begin{array}{l}\text { old } i i+u u \\
\text { (e.g. } i j s / h u i s)\end{array}$ & [-diphthong] & \multicolumn{2}{|c|}{ [+diphthong] } \\
\hline $\begin{array}{l}\text { old } \breve{l}+\breve{u} \\
\text { (e.g. vis/put) }\end{array}$ & \multicolumn{2}{|c|}{ [not narrow] } & [narrow] \\
\hline $\begin{array}{l}\text { old ăllŏl }+d / t \\
\text { (e.g. zout/goud) }\end{array}$ & {$[\mathrm{u}]$} & \multicolumn{2}{|c|}{ [open diphthong] } \\
\hline $\begin{array}{l}\text { non-suffixal } \\
\text { final -ə }\end{array}$ & \multicolumn{2}{|c|}{ [maintained] } & [deleted] \\
\hline
\end{tabular}

The East Flemish dialect area represents a striking example of this, since it partly owes its identity to quite a number of exclusive features, mainly phonological in nature (cf. section 1 above), and partly to a particular combination of features which also occur in the West Flemish or the (southern) Brabantine dialects (cf. Table 7.2).

Another specific instantiation of this type of situation is the terrace-shaped dialect landscape (German 'Staffellandschaft'), such as that found in the traditional Limburg dialects, the Ripuarian dialects of Dutch in the far southeast, and the group of transition dialects in between; cf. 2 above). From the northwest (where western Limburg dialects are spoken), through the centre of the former Princebishopric (the habitat of central and eastern Limburg dialects) to the southeast (Ripuarian) dialect features accumulate to the effect that many local dialects add one or a few features to those shared with the dialect of villages to their (north-) west. To illustrate this for three of the many relevant phonological phenomena, whereas central and eastern Limburg dialects have sandhi voicing (see 1 above), the dialects of the transition area have sandhi voicing as well as the variable deletion of final /n/ in monosyllabic function words (see 2 above) and the Ripuarian dialects have sandhi voicing, n-deletion as well the weakening of both lexical and derived voiced velar fricatives (see Hinskens 1992, section 3.3.2. for a more extensive overview).

4) The traditional classifications in dialect areas (cf. section 3) are based on oppositions in the traditional dialects, but in the last fifty years many changes became active which are shaping different spatial patterns (e.g. devoicing of initial fricatives, extremely velar or even uvular realization of the velar fricatives, new variants of $r$, diphthongization of eeloo, reinforcement of the 'old' diphthongs eilui, i.e. / $/$ i/ and /œy/). In addition, the traditional dialects are losing 'old' features at an increasing speed. 
This book discusses the six main dialect areas of the Dutch dialect landscape, in three chapters each (chs. 9-26). They mainly focus on the phonology and morphosyntax of the traditional dialects. However, for every area we also included a chapter on recent developments on the vertical axis (describing convergence and divergence on the dialectstandard axis) and the horizontal one (cross-dialectal convergence and divergence) within the variational spectrum. The third part of this book, which zooms in on supraregional as well as extra-regional phenomena, includes one chapter (ch. 32) on spatial variation patterns beyond (or besides) the more traditional subdivisions in the dialect landscape.

Section 4 of the present chapter will explain how and to which extent the four preceding considerations played a role in the classification of dialect areas in this book.

\section{Earlier and more recent classifications of the Dutch dialects into dialect areas}

From 1892 onwards several attempts have been made to group the Dutch dialects into a restricted number of dialect areas. In this section four of such proposals will be briefly discussed; each of these attempts is typical of a particular view on the structure of the dialect landscape and of a particular method to establish the kinds of relationships among various dialects. They will be treated here in chronological order.

\subsection{Van Ginneken (1913)}

In his monumental Handboek der Nederlandsche taal (1913, $\left.{ }^{2} 1928\right)$ Van Ginneken published a folding map with a fairly detailed subdivision of the Dutch dialects. This map divides the Dutch language area into five large dialect areas, each neighbouring pair of which is separated by a single line. Every area is rendered in a particular colour and named after an ancient West Germanic tribe:

(I) Friesch 'Frisian', comprising the province of Friesland and also (though in a different shade) North Holland north of the river IJ;

(II) Saksisch 'Saxon', including a large northeastern area from Groningen in the north to the south of the Dutch province of Gelderland;

(III) Hollandsch-Frankisch 'Holland Franconian', a large central and southwestern area from the south of the province of North Holland to the outer southwest (French Flanders);

(IV) Brabantsch-Frankisch 'Brabantine Franconian': this area comprises the southwest of Gelderland (the eastern part of the Maas and Waal rivers area), the southwestern half of North Brabant and the Belgian provinces of Antwerp, South Brabant and East Flanders;

(V) Limburgsch-Frankisch 'Limburg Franconian', a large southeastern area which not only comprises Dutch and Belgian Limburg but also the eastern half of the Dutch province of North Brabant and the eastern edge of the Belgian province of South Brabant. 
Every main area is subdivided into subareas, which are indicated by different patterns of black lines.

Van Ginneken's subdivision was based on dialect oppositions which had come to light in the earliest research on Dutch dialectology, mainly te Winkel (1899-1901, cf. Kruijsen and Van der Sijs 2010: 183), Van Wijk (1907) and Schrijnen (1902). In almost all cases phonological oppositions where involved, although a few demarcations were also based on morphological phenomena.

Van Ginneken's (1913) map is subject to at least three kinds of criticism (cf. also Goossens ${ }^{2}$ 1977: 162-164):

(1) the author is not very explicit about which conglomerate of oppositions/isoglosses were taken into account;

(2) the boundaries are drawn rather inaccurately, although in all fairness we should add that this is mainly due to the state of research at that time;

(3) as was pointed out above, the large dialect areas (with different colours) are demarcated linearly. Later dialect geographical research revealed that the structure of a dialect landscape is much more complex and that dialect areas hardly ever display abrupt transitions. To a large extent this objection was at least partially overcome in later attempts to subdivide the Dutch dialects into (sub)areas.

\subsection{Weijnen $(1958 / 21966)$}

As research in dialect geography progressed, the insight that a dialect landscape does not consist of a linear juxtaposition of homogeneous dialect areas gained more ground. In fact, it constitutes a multi-directional continuum: isoglosses (which are themselves idealizations of gradual transitions) cut through all parts of the language area, although they tend to cluster more strongly in particular transition zones. Today it is commonly accepted that dialect landscapes consists of central areas, where similarity prevails over disparity, and transition areas, where variation prevails over similarity.

Weijnen was the first Dutch dialectologist to adopt this concept in his attempt (1958/ $\left.{ }^{2} 1966\right)$ to subdivide the Dutch language area into dialect areas. Weijnen's folding map displays a number of isoglosses which, because of their tendency to cluster in certain regions, make it possible to discern a number of relatively homogeneous dialect areas. In his comments (1966: 424-477), Weijnen distinguishes six large areas which are no longer designated by names which refer to (historical or mythological) ancient Germanic tribes, but rather by a purely geographical nomenclature:

(I) Northwestern dialects: North Holland north of the river IJ;

(II) Central northern dialects: Holland south of the river IJ and Utrecht (except the eastern part, i.e. the Veluwe region);

(III) Northeastern dialects: approximately the Dutch provinces of Groningen, Drenthe, Overijssel and Gelderland (except the southwestern part) as well as the eastern part of Utrecht (a woody area known as the Veluwe);

(IV) Southwestern dialects: French and West Flanders, Zeeland (except the Land van Hulst region in Zeeland Flanders) and the South Holland island of Goeree-Overflakkee; 
(V) Central southern dialects: the Brabantine provinces of North Brabant (except the southeastern part in the Netherlands), the Belgian provinces of Antwerp and South Brabant and also East Flanders;

(VI) Southeastern dialects: Dutch and Belgian Limburg and the southeastern part of North Brabant.

For each of these six dialect areas Weijnen presents a number of what he calls 'exclusivisms', admitting that their number differed considerably from area to area. The largest numbers are found in the northeastern and the southeastern areas (areas III and VI). Weijnen's map also displays the transition zones, for example between (V) and (VI) (the transition area between Brabantine and Limburg dialects).

In comparison with the preceding subdivision, the one by Weijnen undeniably has a number of advantages. Two of the most important ones are the following: (a) it offers a much better reflection of the nature of the dialect landscape by distinguishing between central and transition areas, and (b) it is based on a broad spectrum of verifiable data. Still, Weijnen's subdivision was also subject to criticism during the last fifty years (cf. also Goossens ${ }^{2}$ 1977: $164-165$ ). We summarize the main objections in three points:

(1) Isoglosses are in fact idealizations of a more complex reality: most of the mapped transitions are quantitatively and/or phonetically gradual.

(2) Isogloss maps of this type mask, at least partially, the reality of the dialect continuum.

(3) The choice of the oppositions/isoglosses is in some respects subjective: the more traditional dialect geographers had a preference for oppositions and isoglosses which render the strongest clustering patterns at the border of the different central areas.

Especially the final two objections informed more recent attempts to subdivide the Dutch dialects (cf. the next two sections).

\subsection{A perception-based dialect map: Daan (1969)}

In order to neutralize or at least minimize the (subjective) part of the dialect geographer in the selection of oppositions to be mapped, Daan (Meertens Instituut) devised a completely different method for mapping affinities and differences between Dutch dialects. She asked several hundred dialect users from all parts of the Netherlands to complete a questionnaire which (among other things) contained the following two questions:

(1) In which place(s) in your region do people speak the same or almost the same dialect as in your town or village?

(2) In which place(s) in your region do people speak a dialect which differs strongly from your own dialect? Can you indicate some differences?

Note that this questionnaire was not distributed in the Dutch-speaking part of Belgium. For her 1969 map, Daan appealed to "Belgian linguists who [unlike their Dutch colleagues] are almost exceptionlessly dialect speakers" [our translation].

The places that informants mentioned in response to question (1) were connected by an arrow; the places that were mentioned in response to question (2) were not connected at 
all. Incidentally, this approach, known as 'pijltjesmethode', lit. 'little arrow method', was developed and first applied by Weijnen (1946 and 1947) for a part of the Dutch language area. This procedure allowed Daan to draw a map which reflected the dialect speakers' awareness of similarities and differences between dialects. This method, know as perceptual dialectology, was later refined by Preston (1981) and, in the Netherlands, by Nerbonne and his research group at the University of Groningen (see ch. 30 in this book). The final results of this inquiry were reflected on Daan's 1969 map. On this map the different dialect areas are rendered by means of different colours.

On the whole, this map does not differ dramatically from that in Weijnen (1958/ ${ }^{2} 1966$ ), although Weijnen did not use colours but drew isoglosses instead. The similarities between the two maps mainly concern the resulting large dialect areas. The resemblances may at least partly be due to some methodological surgery by Daan: where the respondents' data did not correspond to the opinions of professional dialect researchers (such as Daan herself), all kinds of 'corrections' were made. As a matter of fact, this aspect of Daan's research was later vehemently criticized (cf. among others Goossens 1977: 166-168 and section 2.1. of ch. 30 in this book). Another point of criticism related to the fact that in the Dutch-speaking part of Belgium Daan did not rely on laymen's intuitions but on insights of professional people.

The map in Daan (1969) also displays six big dialect areas:

(I) A northwestern area: North Holland (north of the river IJ);

(II) a northeastern area: Groningen, the southeastern part of Friesland (Stellingwerven), Drenthe, Overijssel and Gelderland (except the southwestern part, i.e. the eastern half of the Maas and Waal rivers area);

(III) a central western area: mainly South Holland (with Utrecht functioning as a transition area between II and III, a view that had also been defended in Van Veen 1964);

(IV) a southwestern area, comprising French Flanders, West Flanders and Zeeland (except the Land van Hulst region);

(V) a central southern area: the area of the former Duchy of Brabant plus the northwestern part of Dutch Limburg; East Flanders (including the Land van Hulst) takes an intermediate position between (IV) and (V);

(VI) a southeastern area: Belgian Limburg and Dutch Limburg, except the area north of Venlo.

By using different shades of colours, Daan's map clearly shows the transition character of some areas. Moreover, it fits in better with the concept of the dialect continuum, although the areas with the different (shades of) colours still are separated linearly.

\subsection{A dialectometrical map: Heeringa (2004)}

In the second half of the 1980s, dialectometry was introduced into Dutch dialectology. This mainly originated from a fundamental dissatisfaction with the traditional isogloss method as the device for subdividing dialect landscapes into (sub)areas on the basis of a number of clear-cut oppositions. The main objection against this practice concerned the subjective choice that researchers (e.g. Weijnen 1958, Goossens 1970) made among the vast amount of oppositions or isoglosses. 
Dialectometrists tried to overcome this objection by using methods which would eliminate subjective selections. By using sophisticated quantitative techniques, data could be aggregated concerning very large or even indeterminate numbers of non-preselected linguistic variables. The most interesting dialectometric research with respect to the Dutch dialects has been and is still being carried out at the University of Groningen. In this context we refer to Hoppenbrouwers and Hoppenbrouwers (1988), who applied the feature frequency method (FFM), and to Nerbonne and Heeringa (1998), who introduced the Levenshtein distance algorithm (see ch. 33 in this book and Heeringa 2004 for more details).

In his dissertation, Heeringa (2004, ch. 9) presents two colour maps which offer a synthesis of his dialectometric research into the distances between the Dutch dialects using the Levenshtein distance algorithm. The second map (p. 273) most clearly visualizes the results of his research: by using the whole spectrum of colour shades he describes the Dutch dialect continuum without any abrupt transitions. On the first map (p. 231), the Dutch dialect area is split up into twelve linearly demarcated groups (eleven if we consider Frisian as a separate language). These 'most significant groups' are also reflected hierarchically in a dendrogram (p. 229). This repartition results from a cluster analysis of the RND-transcriptions (1925-1982) from 360 places, which Heeringa selected for his research.

In a number of respects Heeringa's first map does not differ dramatically from Weijnen's $(1958 / 21966)$ or even Daan's (1969) maps. We perceive (a) a northeastern area, traditionally called the 'Saxon' dialects, (b) a southeastern area, traditionally the 'Limburg' dialects, (c) a central southern area that comprises the central and southern part of the former Duchy of Brabant as well as adjacent parts of West Limburg and East Flanders, (d) a southwestern group, mainly West and French Flanders and (e) a large area that covers Holland, Utrecht, the southwestern half of Gelderland and the province of North Brabant.

The main differences with Weijnen's map may be summarized as follows:

(1) The southwestern half of Belgian Limburg is presented as a transition zone between 'real' Limburg dialects and Brabantine ones.

(2) In the southwestern quarter of the Dutch language area, Zeeland received a colour which distinguished it surprisingly strongly from West Flemish; in the same area, a large western part of East Flanders (approximately two thirds of the territory) is displayed as a transition zone between West Flemish and Brabantine dialects.

(3) The northern part of the former Duchy of Brabant (almost the entire province of North Brabant, which Weijnen $(1958 / 21966)$ assigned to the large Brabantine or 'central southern' area) is integrated into a large area which also comprises Holland, Utrecht and the southwestern half of Gelderland (the Maas and Waal rivers area). This is especially surprising, since Heeringa used North Brabantine data that were gathered between 1946 and 1950, although North Brabant only became strongly influenced by the Holland dialects and the standard language in the second half of the twentieth century.

\section{The classification of Dutch dialects in this book}

As was pointed out above, the second part of this book focuses on the variation spectrum in the traditional Dutch dialects. In order to proceed in a well-organized manner, we 
also had to face the problem of subdividing the Dutch dialect area into a number of subareas. As we indicated in section 2, such a division is problematic for several reasons: dialect landscapes are essentially made up of continua (cf. the map on p. 273 in Heeringa 2004). For purely organizational reasons we had to split up the dialects of the Dutch language area into a restricted number of demarcated regions, so that labour could be efficiently divided among the authors of Chs. 9-26, which present a panoramic overview of the Dutch dialects.

Below we briefly discuss the considerations that underlie our classification.

(a) Our classification is primarily based on the traditional dialects. As stated in section 2.4. of this chapter, we are quite aware of the fact that recent developments are generating new patterns of spatial distribution (cf. ch. 32 in this book). In addition, the traditional dialects are gradually losing some of their 'old' characteristics. The spectrum changes: new colours emerge and old colours bleach at different rates, but all in all the spectrum seems to broaden. Taking the more traditional dialects as a point of departure seemed the most appropriate way to proceed, especially since earlier subdivisions of the Dutch dialects (cf. section 2.3. in this chapter) were based on older dialect data and, in spite of bleaching, traditional dialects still have an effect on the newer types of non-standard varieties which are developing. We have tried to anticipate possible disadvantages of this approach by organizing the description of the dialects of the different regions in a particular way. Three chapters are assigned to every region: the first two focus on the phonology and the grammar of the traditional dialect(s), respectively, whereas every third chapter deals with recent developments on the horizontal and vertical axes in a particular region; the design of these regional sections and the three chapters they contain is the subject matter of the following chapter (ch. 8).

(b) The distinction between relatively homogeneous 'central areas' and the relatively heterogeneous 'transition zones' mentioned above was of crucial importance for the subdivision into dialect areas: every area contains one such 'central area' and its borders are situated in typical 'transition zones'. Yet, a linear demarcation of a dialect area always implies a certain amount of arbitrariness: among other things, we are quite aware of the fact that for certain linguistic phenomena transition zones might just as well be assigned to an adjacent area.

(c) As a matter of fact, we also took the older dialect classifications into account (cf. section 3), which after all were based on huge amounts of empirical linguistic research and - in the case of Daan (1969) - on the perceptions of dialect speakers themselves.

Eventually we opted for a classification into six dialect areas, which does not deviate much from that of Weijnen (1958, ${ }^{2}$ 1966), Daan (1969) and De Schutter (1994). Our classification is presented in more detail below:

(1) A southwestern area, which comprises French Flanders (the outer northwest of France), West Flanders, Zeeland (except the Land van Hulst - cf. (2) immediately below) and the South Holland island of Goeree-Overflakkee. The dialects of this area will be dealt with in ch. 9 (phonology), ch. 10 (grammar) and ch. 11 (recent developments). This area is also identified in Weijnen (1958/21966), Daan (1969) and Heeringa (2004), although the latter renders the Zeeland dialects in a slightly different colour. 
(2) An East Flemish area, which covers almost the entirety of the Belgian province of East Flanders, except the southeastern part (the Dender region), which belongs to the Brabantine area (cf. (3) below). The Zeeland Flanders Land van Hulst was assigned to this area as well. Together with the adjacent Land van Waas (East Flanders in Belgium), it in fact constitutes a transition area between East Flemish and Brabantine dialects.

On earlier classification maps, this area was always presented as a vast transition zone between West Flemish (the southwestern area) and the Brabantine area. On the basis of grammatical properties, this is quite defensible (cf. ch. 13), but phonologically it displays so many exclusive and salient features (cf. Taeldeman 2000 and ch. 12 in this book) that we decided to consider it as a dialect area of its own. It will be discussed in chs. 12-14.

(3) A large Brabantine area, which apart from the old Duchy of Brabant (the provinces of South Brabant, Antwerp -both in Belgium- and North Brabant - in the Netherlands) also comprises the eastern half of the Maas and Waal area (the southwestern part of Gelderland in the Netherlands) and the southeastern part of East Flanders (the Dender region in Belgium).

More or less the same area is also identified in Weijnen $\left(1958{ }^{2} 1966\right)$ and in Daan (1969), although both authors consider certain parts of North Brabant as transition zones: the northwestern part is associated with the South Holland dialects in many respects and the southeastern part displays a lot of affinities with the Limburg area. The Brabantine area is dealt with in chs. 15-17.

(4) A southeastern Limburg area, which more or less covers the provinces of Dutch Limburg and Belgian Limburg, although the westerly part of Belgian Limburg in fact constitutes a transition zone to the Brabantine dialects. In some respects the southeast of North Brabant (in the Netherlands) might also be assigned to the southeastern dialect area, but for organizational reasons we integrated this region into the Brabantine dialect area.

The earlier maps, discussed in section 3, show more or less the same Limburg area, although Heeringa's (2004: 231) dialectometrical analyses show that a surprisingly large part of Belgian Limburg constitutes a transition zone to the Brabantine dialects. The Limburg dialects are discussed in chs. 18-20.

(5) A northwestern area, which comprises the provinces of North Holland, South Holland (except the island of Goeree-Overflakkee) and Utrecht. In a number of respects the eastern part of Utrecht (and more particularly the Veluwe region) associates with the northeastern dialect area.

It is for this area that our demarcation displays the most substantial differences compared with earlier classifications. Weijnen (1958/21966) considers the dialects of Utrecht as a distinct central northern group, although on his map it features as a large transition zone between the Holland dialects and the northeastern group (following Van Veen 1964). Daan's map (1969) in fact suggests the same. Heeringa's map (2004: 231) displays a very large area which not only covers Holland and Utrecht but also the largest part of North Brabant and the southwestern half of Gelderland, which in our classification is integrated, at least partially (the region of Veluwe), in the northeastern dialect area. The northwestern dialects are discussed in chs. $21-23$.

(6) A large northeastern area (traditionally referred to as the 'Low Saxon' dialects), which reaches out from Groningen to the eastern edge of Utrecht (the Veluwe) and 
the Gelderland region of the Achterhoek. The dialects of this group are closely related with Low German ('Niederdeutsch'). The northeastern area also includes the southeastern part of Friesland (the so-called Stellingwerven), where people speak a Low Saxon dialect that has been influenced by Frisian (cf. ch. 38 in part IV of this book).

The earlier maps suggest more or less the same spatial pattern, although there are different views concerning the southern border of this area. The maps of Weijnen and Daan suggest that the eastern edge of Utrecht and of Gelderland north of Arnhem should be included, but on Heeringa's map only the northeastern third of Gelderland is part of the northeastern dialect area. The northeastern dialects are dealt with in chs. $24-26$.

It should be pointed out that the West Flemish $(=1)$, the Brabant $(=3)$ and the Limburg dialects $(=4)$ are becoming more heterogeneous as a result of the demographic and social effects of the state borders. For the Limburg dialects this is clear, for instance, by considering recent findings by Keulen (2009) and Hinskens (1992), which suggest that the position of the dialects of the Hoeselt-Bilzen-Hasselt-Zutendaal area (in Belgian Limburg) maintain a stronger position and are less subject to dialect levelling.

For the northeastern dialect area (6) especially, there may be good reasons to distinguish two subareas (Groningen versus 'the rest'), but an even more fine-grained classification might have made the current project unmanageable; the resulting volume would have become unaffordable and less readable. Moreover, many experts classify the dialects of this - fairly large - area as one group (Bloemhoff et al. 2008).

A final remark concerns the non-standard usage in the Noordoostpolder (lit. North East Polder). This rather rural area was reclaimed from the Zuiderzee (nowadays referred to as the IJsselmeer) in 1942. This polder was 'colonized' by people from all parts of the Netherlands, but predominantly from Friesland and the northeasterly provinces. According to Scholtmeijer (1992), a 'fudged lect' has developed here which, also due to intensive contact with the northeastern mainland, has a predominantly Low Saxon flavour. As a result, we have assigned the Noordoostpolder to the northeastern dialect area. Together with the polders of the IJsselmeer which were reclaimed in the 1950s and 1960s, this area will be discussed in chapter 26 (recent developments in the northeastern area), although the language that is used in the younger, more westerly polders is by no means Low Saxon.

\section{References}

Bloemhoff, Henk, Jurjen van der Kooij, Hermann Niebaum and Siemon Reker (eds.)

2008 Handboek Nedersaksische Taal-en Letterkunde. Assen: Van Gorcum.

Claes, Frans M.

1991 Dialectlexicografie bij Kiliaan. Taal en Tongval. Themanummer 4: 155-163.

Daan, Jo

1969 Van randstad tot landrand. Toelichting bij de kaart. In: Jo Daan and Dirk P. Blok (eds.), Dialecten en Naamkunde, Amsterdam: Noord Hollandsche Uitgevers Maatschappij.

De Schutter, Georges

1994 Dutch. In: Ekkehard König and Johan Van der Auwera (eds.), The Germanic Languages, 439-477. London: Routledge. 
Goossens, Jan

1970 De indeling van de Nederlandse dialecten. Driemaandelijkse Bladen 22: 56-73.

Goossens, Jan

1977 Inleiding tot de Nederlandse dialectologie. 2nd edition.Groningen: Wolters-Noordhoff.

Heeringa, Wilbert

2004 Measuring Dialect Pronunciation Differences using Levenshtein Distance. Ph.D. thesis, University of Groningen.

Hinskens, Frans

1992 [1996] Dialect levelling in Limburg. Structural and sociolinguistic aspects. Ph.D. thesis, University of Nijmegen. [Abridged and revised version under the same title. Tübingen: Niemeyer.]

Hinskens, Frans

2009 The erosion of a variable process. The case of $n$-deletion in Ripuarian and Limburg dialects of Dutch. In: Frank Kügler, Caroline Féry and Ruben van de Vijver (eds.), Variation and gradience in phonetics and phonology, 311-350. Berlin/New York: Mouton de Gruyter.

Hoppenbrouwers, Cor and Geer Hoppenbrouwers

1988 De featurefrequentiemethode en de classificatie van Nederlandse dialecten. Tabu 18: $51-92$.

Jellinghaus, Hermann

1892 Die niederländischen Volksmundarten nach den Aufzeichnungen der Niederländer. Norden/ Leipzig: Soltau.

Kilianus Dufflaeus, Cornelius

1599 Etymologicum Teutonicae linguae sive Dictionarium Teutonico-Latinum. Third edition.

Kessler, Brett Antwerpen: Plantyn.

1995 Computational dialectology in Irish Gaelic. Proceedings of the 7th Conference of the Euro-

Keulen, Ronny pean Association for Computational Linguistics, 60-67. Dublin: EACL.

2009 Enkele beschouwingen over de west- en noordgrens van het Limburgs. In: Lei Heijenrath (ed.), Veldeke Jaarboek 2008-2009, 102-116. Roermond: Vereniging Veldeke Limburg.

Kruijsen, Joep and Nicoline van der Sijs

2010 Mapping Dutch and Flemish. In: Alfred Lameli, Roland Kehrein and Stefan Rabanus (eds.), Language and Space: Language Mapping, 180-202. Berlin/New York: Mouton de Gruyter.

Nerbonne John and Wilbert Heeringa

1998 Computationele vergelijking en classificatie van dialecten. Taal en Tongval 50: 164-193.

Preston, Dennis R.

1981 Perceptual Dialectology. Mental maps of United States dialects from a Hawaiian perspective. In: Henry J. Warkentyne (ed.), Papers from the Fourth International Conference on Methods in Dialectology, 192-198. Victoria, B.C.: University of Victoria.

Scholtmeijer, Harrie

1992 Het Nederlands van de Ijsselmeerpolders. Ph.D. thesis, University of Leiden.

Schrijnen, Jos

1903 Benrather-, Urdinger- en Panningerlinie. Tijdschrift voor Nederlandse Taal- en Letterkunde 21: 249-252.

Spruit, Marco R.

2008 Quantitative perspectives on syntactic variation in the Dutch dialects. Utrecht: LOT.

Taeldeman, Johan

2000 Diepe structurerende factoren onder het Oost-Vlaamse klankoppervlak. Taal en Tongval. Themanummer 13: 96-109. 
Te Winkel, Jan

1899-1901 De Noordnederlandsche tongvallen. Atlas van taalkaarten met tekst. Leiden: Brill.

Van Ginneken, Jacques

1913 [1928] Handboek der Nederlandsche taal. Deel I: de sociologische structuur der Nederlandsche taal. [Second edition] Nijmegen.

Van Veen, Teunis

1964 Utrecht tussen oost en west. Assen: Van Gorcum.

Van Wijk, Nicolaas

1907 Vocaalrekking vóór $r+$ dentaal. Tijdschrift voor Nederlandse Taal- en Letterkunde 26: $33-65$.

Weijnen, Antonius A.

1946 De grenzen tussen de Oost-Noordbrabantse dialecten onderling. In: Antonius A. Weijnen, J. M. Renders and Jacobus van Ginneken (eds.), Oost-Noordbrabantse dialectproblemen, 1-15. Amsterdam: Noord Hollandsche Uitgevers Maatschappij.

Weijnen, Antonius A.

1958 [1966] Nederlandse Dialectkunde. [Second edition] Assen: Van Gorcum.

Johan Taeldeman, Ghent (Belgium)

Frans Hinskens, Amsterdam (The Netherlands)

\section{Unravelling the complexities of variation and change in and beyond the present-day dialects of Dutch: Finding one's way through the woods}

1. Introduction

2. Design of the chapters in the region sections

3. What is not in the chapters in the region sections

4. Atlases

5. References

\section{Introduction}

The present chapter contains a reasoned account of the various considerations that underlie the structure of the remainder of this Part II of the volume, i.e. chapters 9 to 26, which constitute the so-called region sections in this book. This chapter discusses the skeleton of the dialectological body, as it is largely stripped bare of flesh and muscles, since it does not contain any linguistic substance (let alone analyses); at the very most it presents a few brief examples to strengthen the argumentation.

For the sake of comparability, the dialects in each of the six regions presented in section 4 of the preceding chapter (Ch. 7) will be discussed according to a fixed format; for each region this format consists of three chapters. In the present chapter the rationale behind the division of labour among the three chapters as well as the overall structure of each of the three chapters is discussed. 